УДК 339:63 + 349.42

DOI: 10.36461/NP.2019.52.3.006

\title{
ПРАВОВОЕ ОБЕСПЕЧЕНИЕ И ПУТИ ПОВЫШЕНИЯ ЭФФЕКТИВНОСТИ ГОСУДАРСТВЕННОГО ЗЕМЕЛЬНОГО НАДЗОРА В ПЕНЗЕНСКОЙ ОБЛАСТИ
}

О. Ф. Кадыкова, канд. экон. наук, доцент; А. П. Дужников, канд. с.-х. наук, доцент; Т. Н. Чуворкина, канд. экон. наук, доцент; А. В. Долбилин, канд. с.-х. наук, доцент

Федеральное государственное бюджетное образовательное учреждение высшего образования «Пензенский государственный аграрный университет»,

Россия, т. (8-412) 628338, e-mail: pr.pravo@mail.ru

Авторами рассмотрена система правового обеспечения организации земельного надзора на региональном уровне, приведены результаты анализа деятельности государственных инспекторов по использованию и охране земель в Пензенской области, представлены нарушения земельного законодательства, определены основные направления повышения эффективности земельного надзора. Проведенный анализ правовых источников по исследуемой проблеме показал, что при осуществлении государственного земельного надзора применяются нормативно-правовые акты разного уровня. Согласно существующему законодательству государственный земельный надзор осуществляется специально уполномоченными федеральными органами исполнительной власти. Среди ведомств наибольшими полномочиями в области земельного надзора обладает Федеральная служба государственной регистрации, кадастра и картографии (далее - Росреестр).

На основе проведенного анализа основных показателей государственного надзора по Пензенской области определена эффективность деятельности Управления Росреестра. Рассмотрены показатели, характеризующие деятельность государственных инспекторов Росреестра по охране и использованию земель за 2015-2018 годы. Приводятся конкретные примеры нарушений земельного законодательства в регионе. Выявлено, что спорные ситуации, возникающие в ходе проведения проверок, связаны с самовольным занятием земельного участка или его использованием без соответствующих документов. Результаты анализа показателей результативности деятельности государственных инспекторов Росреестра по охране и использованию земель в регионе свидетельствуют, что исполнение государственной функции по государственному земельному надзору по Пензенской области находится в пределах нормы. Предлагаемые авторами контрольно-надзорные мероприятия позволят повысить эффективность земельного надзора в Пензенской области.

Ключевые слова: правовое регулирование, государственный земельный надзор, эффективность деятельности органов исполнительной власти.

\section{Введение}

Нормативно-правовая база является основой успешного функционирования деятельности уполномоченных органов исполнительной власти в области земельного надзора. Система правового регулирования отношений, связанных с обеспечением рационального использования и охраны земель, защитой прав и законных интересов собственников, землепользователей, арендаторов, в Российской Федерации носит комплексный характер. [1]

В последние годы в Российской Федерации активно формируется единый механизм правового регулирования использования земельных участков в отведенных границах и в соответствии с их целевым назначением. Органами, осуществляющими надзор за соблюдением земельного законодательства, выступают Федеральная служба государственной регистрации, кадастра и картографии, Федеральная служба по ветеринарному и фитосанитарному надзору, Федеральная служба по надзору в сфере природопользования.

Анализ результатов государственного надзора за соблюдением земельного законодательства позволил выявить земельные правонарушения, определить эфрфективность работы инспекторов государственного земельного надзора, разработать мероприятия по активизации деятельности в исследуемой области.

\section{Методы и материалы}

Результаты проведенного исследования получены на основе использования методов аналогии, абстрактно-логического, аналитического и сравнительно-правовой оценки. 


\section{Результаты}

Наибольшими полномочиями среди ведомств в области земельного надзора обладает Федеральная служба государственной регистрации, кадастра и картографии (далее - Росреестр). Росреестр осуществляет государственный земельный надзор за соблюдением требований земельного законодательства о недопущении использования земельного участка не по целевому назначению, а также о недопущении самовольного занятия земельного участка и др. По Пензенской области земельный надзор осуществляет Управление Росреестра (далее Управление) [2].

Управление осуществляет свою деятельность на основании Постановления Правительства Российской Федерации от 01.06.2009 № 457 «О Федеральной службе государственной регистрации, кадастра и картографии» и Приказа Росреестра от 30.05.2016 № П/0263 «Об утверждении положений о территориальных органах Федеральной службы государственной регистрации, кадастра и картографии по субъектам Российской Федерации».

При осуществлении государственного земельного надзора применяются также нормы, представленные в федеральных законах и подзаконных актах. К федеральному законодательству в исследуемой сфрере относят Конституцию РФ, Земельный кодекс, Гражданский кодекс РФ (статьи 260-287), Кодекс Российской Федерации об административных правонарушениях (статьи 7.1, 7.34, 8.6, 8.8, 20.25), Уголовный кодекс РФ (статьи 170, 254), Гражданский процессуальный кодекс Российской Федерации, Федеральный закон РФ от 24.07.2007 г. № 221-Ф3 «О кадастровой деятельности», Федеральный закон РФ от 26.12.2008 г. № 294-Ф3 «О защите прав юридических лиц и индивидуальных пред- принимателей при осуществлении государственного контроля (надзора) и муниципального контроля». Подзаконный уровень правового регулирования отношений в сфере земельного контроля включает Постановление Правительства Российской Федерации от 02.01.2015 г. № 1 «Об утверждении положения о государственной земельном надзоре», Постановление Правительства Российской Федерации от 26.12.2014 г. № 1515 «Об утверждении Правил взаимодействия фредеральных органов исполнительной власти, осуществляющих государственный земельный надзор, с органами, осуществляющими муниципальный земельный надзор», Приказ Минэкономразвития России 25.09.2017 г. № 478 «Об утверждении перечня должностных лиц Федеральной службы государственной регистрации, кадастра и картографии, имеющих право составлять протоколы об административных правонарушениях, и о признании утратившими силу некоторых приказов Минэкономразвития России».

Специалисты отдела государственного надзора являются государственными инспекторами Пензенской области по использованию и охране земель. Главным государственным инспектором по использованию и охране земель Пензенской области выступает руководитель Управления [13].

В таблице 1 представлены показатели, характеризующие деятельность государственных инспекторов Росреестра по охране и использованию земель за 2015-2018 годы.

В 2018 году Управлением в рамках исполнения функций по осуществлению государственного земельного надзора было проведено 2148 проверок соблюдения земельного законодательства, из них $49 \%$

Динамика основных показателей государственного земельного надзора

Таблица по Пензенской области

\begin{tabular}{|l|c|c|c|c|c|}
\hline \multicolumn{1}{|c|}{ Показатель } & 2015 г. & 2016 г. & 2017 г. & 2018 г. & $\begin{array}{c}\text { Базисный темп } \\
\text { роста, \% }\end{array}$ \\
\hline Количество инспекторов, ед. & 44 & 38 & 32 & 32 & 72,7 \\
\hline Количество проверок - всего, ед. & 4238 & 3529 & 2220 & 2148 & 50,7 \\
\hline $\begin{array}{l}\text { в том числе: } \\
\text { плановых проверок }\end{array}$ & 3187 & 2478 & 1994 & 1090 & 34,2 \\
\hline внеплановых проверок & 1051 & 1051 & 1126 & 1058 & 100,7 \\
\hline Выявлено нарушений, ед. & 1039 & 1580 & 1409 & 1309 & 125,9 \\
\hline Устранено нарушений, ед. & 460 & 430 & 453 & 550 & 119,6 \\
\hline $\begin{array}{l}\text { Привлечено к административной ответ- } \\
\text { ственности, лиц }\end{array}$ & 951 & 1370 & 894 & 702 & 73,8 \\
\hline Сумма наложенных штрафов, тыс. руб. & 4448,0 & 10243,6 & 6967,8 & 5150,3 & 115,8 \\
\hline Сумма взысканных штрафов, тыс. руб. & 2281,9 & 6441,5 & 4524,0 & 4503,8 & 197,4 \\
\hline
\end{tabular}


Таблица 2

Виды земельных правонарушений в Пензенской области в 2018 году

\begin{tabular}{|l|c|c|}
\hline \multicolumn{1}{|c|}{ Вид нарушения } & $\begin{array}{c}\text { Выявлено } \\
\text { нарушений }\end{array}$ & $\begin{array}{c}\text { Наложено } \\
\text { штрафов } \\
\text { (\% к итогу) }\end{array}$ \\
\hline $\begin{array}{l}\text { Самовольное занятие земельного участка или использование зе- } \\
\text { мельного участка без оформленных в установленном порядке } \\
\text { правоустанавливающих документов на землю (ст. 7.1 КоАП РФ) }\end{array}$ & 1019 & 82,0 \\
\hline $\begin{array}{l}\text { Невыполнение в установленный срок предписания государствен- } \\
\text { ного инспектора, по устранению нарушений земельного законода- } \\
\text { тельства (ст. 19.5 КоАП РФ) }\end{array}$ & 78 & 12,0 \\
\hline $\begin{array}{l}\text { Использование земель не по целевому назначению, неиспользо- } \\
\text { вание земельных участков, а также невыполнение обязанностей } \\
\text { по приведению земель в состояние, пригодное для использования } \\
\text { по целевому назначению (ст. 8.8 КоАП РФ) }\end{array}$ & 21 & 1,6 \\
\hline $\begin{array}{l}\text { Неповиновение распоряжению государственного инспектора или } \\
\text { препятствование выполнения им государственной службы (ст. } \\
19.4 \text { КоАП РФ) }\end{array}$ & 11 & 1,4 \\
\hline Неуплата административного штрафа в срок (ст. 20.25 КоАП РФ) & 19 & 1,6 \\
\hline Прочие земельные правонарушения & 161 & 1,4 \\
\hline
\end{tabular}

внеплановых, что в 2 раза выше уровня 2015 года. Это связано, прежде всего, с изменением отдельных положений законодательства о государственном земельном надзоре, расширяющих перечень оснований для проведения внеплановых проверок. В 2015 году ввели такое понятие, как «административное обследование земельного участка», подразумевающее визуальное обследование земельного участка по его внешним границам, а также получение инспекторами необходимой документарной информации о данном объекте проверки в установленном порядке и официально. В результате исследования полученных результатов, при обнаружении признаков нарушения земельного законодательства формируется акт административного обследования, являющийся основанием для проведения внеплановой выездной проверки [7].

По результатам проверочных мероприятий было выявлено 1309 нарушений. К административной ответственности привлечены 702 нарушителя земельного законодательства. Сумма наложенных штрафов составила 5,15 млн. руб., из них взыскано 4,50 млн. руб.

В 2018 году, по сравнению с 2015 годом, количество проверок снизилось на $49,3 \%$, что связано с уменьшением числа обращений физических и юридических лиц. За исследуемый период увеличилось количество выявленных и устраненных нарушений земельного законодательства на 25,9 и 19,6 \% соответственно. В 2018 году сумма наложенных и взысканных штрафов больше, чем в 2015 году, на 102,3 и 2221,9 тыс. руб. соответственно.
Результаты проверок показали, что в настоящее время основным видом нарушения земельного законодательства является самовольное занятие земельного участка или части земельного участка (табл. 2).

В отчетном году распространенными правонарушениями выступали также невыполнение в установленный срок предписания государственного инспектора по устранению нарушений земельного законодательства [13].

По итогам 2018 года из 1309 нарушений земельного законодательства было устранено 550.

Эффективность деятельности государственных инспекторов по использованию и охране земель оценивается согласно требованиям приказа Росреестра от 30.12.2015 № П/693 «Об оценке эффрективности и результативности исполнения территориальными органами Росреестра полномочий по государственному контролю (надзору)».

Показатели результативности исполнения государственной функции по государственному земельному надзору по Пензенской области в 2017-2018 гг. представлены в таблице 3.

За отчетный период нагрузка на одного инспектора составила $196 \%$, что на $11 \%$ ниже уровня предыдущего года. За 20172018 годы планы проверок по государственному земельному контролю выполнены на $86 \%$ [15].

В отчетном году доля проведенных проверок (по итогам которых были выявлены нарушения) и доля нарушений (которые устранены или по которым были приняты меры за не устранение нарушений в уста- 
Показатели эфрфективности земельного надзора в Пензенской области в 2017-2018 г2.

\begin{tabular}{|l|c|c|c|}
\hline \multicolumn{1}{|c|}{ Показатель } & 2017 г. & 2018 г. & $\begin{array}{c}\text { Aбсолютный } \\
\text { прирост }\end{array}$ \\
\hline Выполнение плана, \% & 86,0 & 86,2 & 0,2 \\
\hline Нагрузка на одного инспектора, \% & 207,0 & 196,0 & -11 \\
\hline $\begin{array}{l}\text { Доля проверок, по итогам которых были выявлены нару- } \\
\text { шения, \% }\end{array}$ & 43,0 & 56,8 & 13,8 \\
\hline $\begin{array}{l}\text { Доля нарушений, которые устранены или по которым } \\
\text { были приняты меры за неустранение нарушений в уста- } \\
\text { новленный срок, \% }\end{array}$ & 72,9 & 75,0 & 2,1 \\
\hline $\begin{array}{l}\text { Доля штрафов, уплаченных или переданных для взыска- } \\
\text { ния в службу судебных приставов, \% }\end{array}$ & 85,8 & 94,0 & 8,2 \\
\hline Доля отмененных постановлений, \% & 6,7 & 2,5 & $-4,2$ \\
\hline $\begin{array}{l}\text { Экономическая эфффективность осуществления государ- } \\
\text { ственной функции, коэффициент }\end{array}$ & 0,4 & 0,34 & $-0,06$ \\
\hline
\end{tabular}

новленный срок, от общего числа выданных предписаний об устранении нарушений земельного законодательства) составила 56,8 и $75 \%$ соответственно. По данным показателям наблюдается положительная динамика.

В 2018 г. по сравнению с 2017 г. выросла доля штрафров, уплаченных или переданных для взыскания в службу судебных приставов на $8,2 \%$. В целом, экономическая эфрфективность осуществления государственной функции по земельному надзору находится в пределах нормы и составляет 0,34.

Суммарная бальная оценка результативности деятельности органа исполнительной власти по осуществлению государственного земельного надзора по Пензенской области по итогам 2018 г. составила более 23 баллов. За данное достижение присваивается оценка «хорошо» [8].

Для повышения эффективности государственного земельного надзора в Пензенской области предлагаем следующие мероприятия:

- расширить штат государственных инспекторов, чтобы на каждого из них возлагалась реальная нагрузка, при которой возможно проведение профилактической работы с землевладельцами по разъяснению их обязанностей;

- улучшить техническое оснащение государственных инспекторов за счет применения современной компьютерной техники, спутникового геодезического оборудования, новых транспортных средств [11];

- усовершенствовать электронный картографрический материал, полученный космосъемкой территории, для детального анализа и изучения состояния земель в допроверочных мероприятиях и в целях мониторинга характеристик земель (их освоенности, наличия объектов на них и ограждений);
- внести изменения в Кодекс об административных правонарушениях, наделив специалистов органов местного самоуправления, уполномоченных на осуществление муниципального земельного контроля, полномочиями по составлению протоколов об административных правонарушениях и привлечению к административной ответственности виновных лиц (в целях снижения нагрузки на государственных инспекторов);

- урегулировать межведомственное взаимодействие надзорных организаций в сфрере соблюдения земельного законодательства с УМВД России по Пензенской области во избежание конфликтных ситуаций при проведении проверок [8];

- повысить взаимодействие Управления Росреестра по Пензенской области и органов муниципального земельного контроля с целью своевременного выявления и пресечения земельных правонарушений на территории поселков, городов и других муниципальных образований;

- повысить эффективность административных обследований путем использования беспилотных летательных аппаратов [7];

- усилить ответственность собственников земельных участков и землепользователей за неисполнение земельного законодательства за счет увеличения размера взысканий.

Реализация предлагаемых мероприятий позволит повысить результативность деятельности органа исполнительной власти по осуществлению государственного земельного надзора в регионе.

\section{Заключение.}

В Пензенской области за 2015-2018 гг. в результате проведенных мероприятий по государственному земельному надзору увеличилось число выявленных и устраненных нарушений земельного законодательства, несмотря на снижение общего 
количества проверок. За исследуемый период к административной ответственности было привлечено 3917 нарушителей земельного законодательства. Сумма взысканных штрафов составила более 17,7 млн. рублей. Экономическая эффрективность осуществления государственной функции по земельному контролю в регионе находится в пределах нормы. В перспективе необходимо активизировать применение контрольно-надзорных мероприятий в сорере соблюдения земельного законодательства.

\section{Лumepamypa}

1. Земельный кодекс Российской Федерации от 25.10.2001 № 136-Ф3 // Официальный интернет-портал правовой информации. [Электронный ресурc] URL: http://www. pravo. gov. ru_(дата обращения 07.10.2019).

2. Постановление Правительства Российской Федерации от 01.06.2009 № 457 «О Федеральной службе государственной регистрации, кадастра и картографии» // Собрание законодательства РФ. - 2009. - № 25. - Ст. 3052.

3. Постановление Правительства Российской Федерации от 02.01.2015 г. № 1 «Об утверждении Положения о государственной земельном надзоре» // Собрание законодательства РФ. 2015. - № 2. - Ст. 514.

4. Приказ Росреестра от 04.06.2019 № П/0218 «Об утверждении Регламента Федеральной службы государственной регистрации, кадастра и картограффии» // Офрициальный интернетпортал правовой информации. [Электронный ресурc] URL: http://www. pravo. gov. ru (дата обращения 07.10.2019).

5. Беляев, В. П. Контроль и надзор: проблемы разграничения / В. П. Беляев // Актуальные проблемы российского права. - 2017. - № 4 (77) апрель. - С. 199-207.

6. Бондин, И. А. Методы оценки результативности и эффективности сельскохозяйственного производства / И. А. Бондин, Н. Н. Бондина, О. В. Лаврина // Аграрный научный журнал. - 2015. № 5. - С. 68-73.

7. Дужников, А. П. Административное обследование как метод выявления нарушений земельного законодательства / А. П. Дужников, К. В. Секрет // Энергосберегающие технологии в ландшафтном земледелии: Сборник материалов Всероссийской научно-практической конференции, посвященной 65-летию кафедры «Общее земледелие и землеустройство» и Дню российской науки. - 2016. - С. 278-281.

8. Дужников, А. П. Анализ и оценка эффективности государственного земельного надзора в Пензенской области / А. П. Дужников, А. С. Малевинская // Инновационные идеи молодых исследователей для агропромышленного комплекса России: Сборник материалов Международной научно-практической конференции молодых ученых. - 2017. - С. 97-100.

9. Кадыкова, О. Ф. Право (гражданское): учебное пособие / О. Ф. Кадыкова. - Пенза: РИО ПГСХА, 2015. - 145 c.

10. Кадыкова, О.Ф.Правовое обеспечение осуществления и защиты прав хозяйствующих субъектов / О. Ф. Кадыкова, Т. Н. Чуворкина // Проблемы управления, экономики и права в общегосударственном и региональном масштабах: Сборник статей $\mathrm{V}$ Всероссийской научнопрактической конференции. - Пенза: РИО ПГАУ. - 2018. - С. 64-67.

11. Липски, С. А. К вопросу об информационном обеспечении контрольно-надзорных функций в сорере землепользования / С. А. Липски, А. Д. Демьянова // Землеустройство, кадастр и мониторинг земель. - 2017. - № 12. - С. 13-18.

12. Сафронова, А. О. О совершенствовании государственного земельного надзора на современном этапе / А. О. Сафронова // Кадастр недвижимости и мониторинг природных ресурсов. 2015. - C. $108-110$.

13. Редькина, С. В. Организация государственного земельного надзора в Пензенской области / С. В. Редькина, М. С. Акимова, Н. Ю. Улицкая // Вектор экономики: Электронный научный журнал. - 2018. - № 11. [Электронный ресурc] URL: http://www. vectoreconomy.ru/images/ publications/2018/11/regionaleconomy/Redkina Akimova Ulitskaya. pdf (дата обращения 14.10.2019)

14. Чуворкина, Т. Н. Правовые аспекты государственной поддержки субъектов малого агробизнеса (на примере Пензенской области) / Т. Н. Чуворкина, О. Ф. Кадыкова // Международный сельскохозяйственный журнал. - 2015. - № 6. - С. 35-38.

15. Федеральная служба государственной регистрации, кадастра и картографии «Росреестр»: офиц. сайт. [Электронный ресурc] URL: https://rosreestr. ru_/ (дата обращения 07.10.2019).

16. Agrarian and industrial complex innovative system formation: the mechanism of public- private partnership / I. G. Ushachev, I. S. Sandu, V. I. Nechaev. -Moscow: FGBNU VNIIESH, 2015. - 135 p.

17. Formation of innovation system of aic: mechanism of transfer of innovations / I. G. Ushachev, I. S. Sandu et all. - Moscow: Scientific consultant, 2019. - 186 p.

18. Models of investment appeal of agribusiness in Russian regions / D. Samygin, N. Baryshnikov, N. Shlapakova // J. Ponte - 2017. - Vol. 73/ - № 2. - P. 344-351. doi: 10.21506/j. ponte.2017.2.29 
UDC 339:63 + 349.42

DOI: 10.36461/NP.2019.52.3.007

\section{LEGAL SUPPORT AND WAYS TO INCREASE THE EFFICIENCY OF STATE LAND SUPERVISION IN THE PENZA REGION}

O. F. Kadykova, Candidate of Economic Sciences, Assistant-Professor; A. P. Duzhnikov, Candidate of Agricultural Sciences, Assistant-Professor; T. N. Chuvorkina, Candidate of Economic Sciences, Assistant-Professor; A. V. Dolbilin, Candidate of Agricultural Sciences, Assistant-Professor

Federal State Budgetary Educational Institution of Higher Education «Penza State Agrarian University», Russia, t. (8-412) 628338, e-mail: pr. pravo@mail.ru

The article presents the system of legal support for the organization of land supervision at the regional level, the results of the analysis of the activities of state inspectors on the use and protection of land in the Penza region are presented, violations of land legislation are presented, the main directions for improving the effectiveness of land supervision are identified. The analysis of legal sources on the studied problem showed that in the implementation of state land supervision regulatory and legal acts of different levels are applied. According to existing legislation, state land supervision is carried out by specially authorized federal executive bodies. Among departments, the Federal State Registration, Cadastre and Cartography Service (hereinafter referred to as the Rosreestr) has the largest powers in the field of land supervision.

Based on the analysis of the main indicators of state supervision in the Penza region, the effectiveness of the Rosreestr Directorate is determined. The indicators characterizing the activities of state inspectors of the Rosreestr on the protection and land use for 2015-2018 are considered. Concrete examples of violations of land legislation in the region are given. It was revealed that controversial situations arising in the course of inspections are related to unauthorized occupation of a land plot or its use without appropriate documents. The results of the analysis of the performance indicators of the state inspectors of Rosreestr on the protection and land use in the region indicate that the performance of the state function of state land supervision in the Penza region is within the normal range. The control and supervision measures proposed by the authors allow to improve the effectiveness of land supervision in the Penza region.

Key words: legal regulation, state land supervision, performance of executive authorities.

\section{References:}

1. The Land Code of the Russian Federation of October 25, 2001 No. 136-FZ // Official Internet portal of legal information. [Electronic resource] URL: http: //www. pravo. gov. ru (accessed October 7, 2019).

2. Decree of the Government of the Russian Federation dated 01.06.2009 No. 457 «On the Federal Service for State Registration, Cadastre and Cartography» // Collection of legislation of the Russian Federation. - 2009. - No. 25. - Art. 3052.

3. Decree of the Government of the Russian Federation dated 02.01.2015, No. 1 «On approval of the Regulation on state land supervision» // Collection of legislation of the Russian Federation. - 2015. No. 2. - Art. 514.

4. Rosreestr's order dated 04.06.2019 No. П / 0218 «On approval of the Regulations of the Federal Service for State Registration, Cadastre and Cartography» // Official Internet portal of legal information. [Electronic resource] URL: http: //www. pravo. gov. ru (accessed October 7, 2019).

5. Belyaev, V. P. Control and supervision: problems of differentiation / V. P. Belyaev // Actual problems of Russian law. - 2017. - No. 4 (77) April. - p. 199-207.

6. Bondin, I. A. Methods for assessing the effectiveness and efficiency of agricultural production / I. A. Bondin, N. N. Bondina, O. V. Lavrina // Agricultural scientific journal. - 2015. - No. 5. - p. 68-73.

7. Duzhnikov, A. P. Administrative examination as a method for detecting violations of land legislation / A. P. Duzhnikov, K. V. Sekret // Energy-saving technologies in landscape farming: a collection of materials of the All-Russian scientific-practical conference dedicated to the 65th anniversary of the Department of General Agriculture and Land Management and the Day of Russian Science. - 2016.-- p. 278-281.

8. Duzhnikov, A.P. Analysis and evaluation of the effectiveness of state land supervision in the Penza region / A. P. Duzhnikov, A. S. Malevinskaya // Innovative ideas of young researchers for the agro-industrial complex of Russia: Collection of materials of the International scientific-practical conference of young scientists. - 2017.-- p. 97-100.

9. Kadykova, O. F. Law (civil): textbook / O. F. Kadykova. - Penza: RIO PSAA, 2015.-- 145 p. 
10. Kadykova, O. F. Legal support for the implementation and protection of the rights of business entities / O. F. Kadykova, T. N. Chuvorkina // Problems of management, economics and law at the national and regional scales: Collection of articles of the $\mathrm{V}$ All-Russian scientific-practical conference. - Penza: RIO PSAU. - 2018.-- p. 64-67.

11. Lipsky, S. A. To the issue of information support of control and supervisory functions in the field of land use / S. A. Lipsky, A. D. Demyanova // Land management, land monitoring and cadaster. - 2017. No. 12. -p. 13-18.

12. Safronova, A. O. On improving state land supervision at the present stage / A. O. Safronova // Real estate cadastre and monitoring of natural resources. - 2015.-- p. 108 - 110.

13. Redkina, S. V. Organization of state land supervision in the Penza region / S. V. Redkina, M. S. Akimova, N. Yu. Ulitskaya // VectorEconomy: Electronic Scientific Journal. - 2018. - No. 11. [Electronic resource] URL: http://www. vectoreconomy. ru/images/publications/2018/11/regionaleconomy/ Redkina_Akimova_Ulitskaya.pdf (accessed October 14, 2019)

14. Chuvorkina, T. N. Legal aspects of state support of small agribusiness entities (on the example of the Penza region) / T. N. Chuvorkina, O. F. Kadykova // International Agricultural Journal. - 2015. - No. 6. p. 35-38.

15. Federal service of state registration, cadastre and cartography «Rosreestr»: official website. [Electronic resource] URL: https://rosreestr. ru / (accessed 07.10.2019).

16. Agrarian and industrial complex innovative system formation: the mechanism of public- private partnership / I. G. Ushachev, I. S. Sandu, V. I. Nechaev. -Moscow: FGBNU VNIIESH, 2015. - 135 p.

17. Formation of innovation system of aic: mechanism of transfer of innovations / I. G. Ushachev, I. S. Sandu et all. - Moscow: Scientific consultant, 2019. - 186 p.

18. Models of investment appeal of agribusiness in russian regions / D. Samygin, N. Baryshnikov, N. Shlapakova // J. Ponte - 2017. - Vol. 73/ - № 2. - P. 344-351. doi: 10.21506/j. ponte.2017.2.29 